\title{
New Perspectives on Hepatitis E
}

\author{
Kenneth C. Hyams, MD, MPH
}

\begin{abstract}
Address
Department of Veterans Affairs, Office of Public Health and Environmental Hazards, 810 Vermont Avenue NW, Washington, DC, USA. E-mail hyamsk@mail.va.gov
\end{abstract}

Current Gastroenterology Reports 2002, 4:302-307

Current Science Inc. ISSN I522-8037

Copyright @ 2002 by Current Science Inc.

The infectious agent causing epidemic non-A, non-B hepatitis was identified in 1983 from a human challenge experiment. The novel hepatitis E virus (HEV) subsequently was cloned in 1990 and the genome sequenced. HEV transmission is highly endemic in Asia, the Middle East, and Africa. Fecal contamination of drinking water is the most common mode of spread. Although usually asymptomatic, HEV infection can cause fulminant hepatitis. Recent studies indicate that hepatitis $\mathrm{E}$ may be a zoonotic disease, with pigs and possibly rats serving as reservoirs for human infection. A recombinant $\mathrm{HEV}$ vaccine is currently in phase III clinical trials. The characterization of the major types of viral hepatitis during the last 20 years illustrates how modern genetic technology has revolutionized research in infectious diseases. Within less than two decades of the discovery of HEV, its epidemiology has been described, serologic tests have been developed, and a candidate vaccine has been evaluated in clinical trials.

\section{Introduction}

It has been known for decades that there are two major types of acute hepatitis caused by an infectious agent: one transmitted by percutaneous exposure and one by the oral route. The leading causes of these two forms of hepatitis-hepatitis A and hepatitis B-have been recognized since the 1940s. However, it became clear after the isolation of the hepatitis A (HAV) and hepatitis B virus (HBV) that there were additional causes of both the parenteral and enteric types of this disease [1•].

The discovery and characterization of the other major types of viral hepatitis during the last 20 years illustrate how modern technology has revolutionized research in infectious diseases. As a result of these accomplishments, our understanding of viral hepatitis has advanced rapidly. Hepatitis E is one of the most recently identified forms of what could previously only be called "non-A, non-B hepatitis" [2].

\section{Hepatitis E Virus}

An early indication that there was an enterically transmitted cause of viral hepatitis, other than HAV, came from large epidemics of acute hepatitis that were observed in the 1950s in the Indian subcontinent [3-5]. These epidemics apparently were caused by an enterically transmitted agent based on evidence of recent fecal contamination of water supplies. However, few outbreak patients had indications of acute HAV infection, and most had serologic evidence of prior immunity to hepatitis A. Consequently, another form of hepatitis was suspected that was initially called epidemic or enterically transmitted non-A, non-B hepatitis [2].

Confirmation of the existence of a novel hepatitis $\mathrm{E}$ virus (HEV) came in 1983 from a human challenge experiment [6]. A researcher ingested pooled stool extracts from cases of epidemic non-A, non-B hepatitis. The volunteer subsequently developed typical icteric hepatitis without serologic evidence of either hepatitis A or B. Virus-like particles, 27 to $30 \mathrm{~nm}$ in diameter, were identified in the volunteer's stool samples by immune electron microscopy (IEM). Antibodies to these particles were found by IEM in the sera of other patients who were presumed to have had epidemic non-A, non-B hepatitis. Cynomolgus monkeys also developed hepatitis after being inoculated intravenously with the virus obtained from the volunteer's stool [6••].

$\mathrm{HEV}$ was cloned in 1990, and the entire genome was subsequently sequenced [7-9]. HEV was found to be a single-stranded, positive-sense RNA virus, $7.2 \mathrm{~kb}$ in length. The genome contains three overlapping open reading frames [8]. It is a spherical virus, probably icosahedral in shape, without an envelope. HEV was originally classified in the family Caliciviridae, although recent studies have determined that its genetic sequence is not closely related to that of any other virus [10]. Currently, there are at least four major genotypes of HEV that can be divided into nine groups, but there may be only one serotype [11,12]. Interestingly, strains of this virus tend to be similar genetically within geographic regions where transmission occurs. Genotype 1 is found in Africa and Asia; genotype 2 was isolated from an outbreak in Mexico; genotype 3 was obtained from two patients in the United States; and genotype 4 is found in China.

Several species of nonhuman primates can be infected with HEV [13]. In nature, recent evidence indicates that swine, rats, chickens, and other animals are infected with viruses related to $\mathrm{HEV}[14 \bullet, 15,16]$. Importantly, the HEV strains (genotype 3) from two patients who developed hepatitis $\mathrm{E}$ in the United States are closely related to swine HEV $[17 \bullet \bullet]$. One of these patients had no history of foreign travel. The other US patient had traveled to Mexico; this patient's HEV strain was capable of infecting pigs [18]. 
However, human isolates of HEV from Asia and Mexico did not cause disease in pigs in another study [19]. Notably, among herds in the midwestern United States, most swine aged greater than 3 months have been found to be seropositive for antibody to HEV [14•]. Additionally, it has been possible to infect rhesus monkeys and chimpanzees with swine HEV [18]. Taken together, the latest findings suggest that there could be one or more animal reservoirs of HEV. Hepatitis E may therefore be a zoonotic disease [20].

\section{Epidemiology}

Because of the unique character and broad host range of this virus, HEV is not readily comparable with other infectious agents. The unusual nature of HEV is further reflected in its distinctive epidemiology.

HEV transmission is highly endemic in south and southeast Asia, the Middle East, and North Africa [2]. Epidemic transmission was also observed in 1986 in two rural villages in Mexico [21], but evidence of transmission in other areas of central and South America has been infrequent [11]. Among the planet's 6 billion people, an estimated 2 billion have been infected with HEV, compared with 5 billion with $\mathrm{HAV}$, the other major enterically transmitted cause of viral hepatitis [13].

$\mathrm{HEV}$, which is found in the feces during active infection, is spread most often through fecal contamination of drinking water [2] and possibly food [22]. Unlike HAV, which is highly infectious, person-to-person or interfamilial transmission is uncommon [23], but HEV may be transmitted vertically from pregnant mothers to their infants [24]. As with HAV, neither sexual nor parenteral contact appears to be an important mode of HEV transmission $[25,26]$.

As noted previously, the existence of HEV first became known from investigations of large epidemics of acute hepatitis. In some endemic regions, recurring epidemics have been a problem [2]. Gross fecal contamination of drinking water has been the major source of epidemic transmission $[3,5,27]$. Recent studies indicate that HEV transmission increases during both flooding and drought in areas where rivers are used for potable water, washing, and waste disposal [28]. Flooding increases cross-contamination of drinking water with human and animal feces [29], and drought is thought to increase the concentration of infectious particles [30].

Although HEV is a common cause of large waterborne epidemics, sporadic infection probably accounts for more clinical cases in regions that are endemic for HEV transmission $[31,32]$. In these tropical and semitropical regions, HEV is often the most common cause of acute hepatitis among adults. The major risk factors for sporadic infection have not been clearly determined [2].

One of the most interesting aspects of HEV transmission is that it does not occur in some developing regions, unlike HAV infection, which can be found everywhere. Most notably, HEV infection has been documented infre- quently in Latin America, where other enteric infections are prevalent [2]. Another mystery is why the prevalence of antibody to HEV (anti-HEV), which indicates past infection, is much lower than the prevalence of HAV infection in regions that are endemic for both hepatic diseases. Unlike a very high prevalence of anti-HAV starting in early childhood, the prevalence of anti-HEV increases slowly among children, rises rapidly during young adulthood, and levels out among adults at around $10 \%$ to $40 \%$ [33•]. It is unclear why HEV antibody prevalence does not steadily increase among older individuals, who presumably are exposed to contaminated water and food along with the rest of the local population. In some highly endemic areas the prevalence of anti-HEV can be greater than $60 \%$, but the level of infection does not reach that of HAV [34].

Transmission of HEV has been found infrequently within developed countries [2,35]. Correspondingly, the prevalence of antibody to HEV is much lower (0.5\% to $4 \%)$ in developed countries than in endemic regions [33•]. However, the prevalence of anti-HEV is not zero, despite the fact that endemic HEV transmission has not been confirmed in North America or Europe. Although some HEV infections may have been acquired by individuals during travel to endemic regions [36,37], there is often no history of foreign travel among anti-HEV-positive residents of Western countries. Therefore, it is unclear whether these antibodies represent prior asymptomatic HEV infection, cross-reactivity with other infectious agents, or false-positive test results [2]. The two reported cases of acute HEV infection acquired within the United States with viral strains genetically similar to swine HEV indicate cross-infection with animals [17••]. In support of this possibility, recent studies indicate that the prevalence of antibody to HEV is higher among individuals who work closely with swine [38].

Travelers from developing countries are seldom infected with HEV, even when living for long periods of time in endemic regions $[33 \bullet, 39]$. Also, no outbreak of HEV has ever been documented among deployed US military personnel [40]. HEV has been a problem for some French forces but has been less of a problem for other European troops deployed to endemic areas [41,42].

Clearly, the epidemiology of hepatitis E differs substantially from that of HAV infection, the other major hepatitis virus spread by the fecal-oral route. In contrast to $\mathrm{HAV}$, which infects nearly all young children in developing countries and results in protective immunity during adulthood, a large proportion of the adult population remains susceptible to HEV infection in endemic regions. Additionally, travelers to endemic regions are at much lower risk of hepatitis $\mathrm{E}$ than of hepatitis A. These epidemiologic characteristics of HEV transmission indicate that this virus cannot spread as readily as HAV, possibly because less virus is excreted in the stool, a relatively larger infective dose is required, or HEV is less able to survive in the environment than is HAV [2]. 


\section{Pathogenesis and Immunity}

HEV causes an acute, self-limited infection, which is most often asymptomatic. The pathogenesis of the liver disease when clinical infection develops is not well understood. In a study of HEV-infected cynomolgus monkeys, morphologic analysis indicated that hepatocytolysis was immune-mediated and not caused by a direct cytopathic effect of the virus [43]. Histologic examination of the liver during HEV infection generally shows changes similar to those with other types of viral hepatitis with no zonal pattern of hepatocyte injury; many patients have a cholestatic type of hepatitis [2].

The mean incubation period from exposure to symptomatic disease is about 40 to 45 days (range, 4 to 10 weeks) $[2,33]$. Unusual for viral causes of hepatitis, larger infective doses of HEV may shorten the incubation period, increase the likelihood of developing clinical disease, and lead to a higher case fatality rate $[27,44]$. Although children can develop symptomatic infection [45,46], acute hepatitis E is most often observed among young adults in the second to fourth decade of life $[3,5,27]$. In hepatitis E outbreaks, attack rates have varied from $3 \%$ to $30 \%$ among adults and from less than $1 \%$ to $10 \%$ among children [2]. It is unclear why clinical disease appears to be more common among young adults.

The illness caused by HEV infection is similar to other types of viral hepatitis [21]. The most prominent symptoms and signs include flulike complaints, nausea, abdominal pain, jaundice, and an enlarged, tender liver. Typically, there is a rise in serum levels of conjugated bilirubin, alanine aminotransferase, aspartate aminotransferase, and alkaline phosphatase just before symptoms begin. After individuals develop symptomatic infection, their recovery usually occurs within 2 to 8 weeks $[2,33 \bullet]$. Chronic infection and liver disease have not been observed following HEV infection. In addition, viral shedding in stool usually lasts for only a brief period: HEV is excreted beginning about 1 week prior to the onset of symptoms, and it persists for only about 2 to 4 weeks [2]. HEV probably reaches the gastrointestinal tract in bile, which contains infectious virus during active replication of HEV [2].

The mortality rate from HEV infection is less than $1 \%$ [2]. HEV infection can, however, cause fulminant hepatitis [47]. Severe disease develops most often in pregnant women in their third trimester $[27,31]$. The mortality rate is as high as $20 \%$ among pregnant women [5]. This is unique among the various types of viral hepatitis, which generally do not cause fulminant disease during pregnancy [48]. Infants infected during pregnancy appear to have a high mortality rate as well [24].

The nature of the immune response following HEV infection is not as well understood as for other types of viral hepatitis. IgM antibody to HEV is detectable about 3 to 8 weeks following infection, at around the same time that clinical disease develops [2]. IgG anti-HEV develops a few days after IgM antibody. Anti-HEV IgM lasts for several months, and anti-HEV IgG is detectable for at least several years following infection $[49,50]$.
Although recent infection appears to confer protection from disease, it is unknown how long immunity persists. The repeated occurrence of epidemics in certain endemic regions indicates either that immunity is not long-lasting or that a minority of the population has been infected with HEV at any one time [2]. In studies of cynomolgus monkeys, protection against hepatitis $\mathrm{E}$ was provided by passive immunity with plasma containing HEV antibodies [51,52]. The effectiveness of passive immunity indicates that humoral immunity is important in preventing disease and possibly infection. However, the titers of IgG anti-HEV drop relatively quickly after natural infection, which may indicate loss of immunity. The role of cell-mediated immunity is unknown.

\section{Diagnosis}

Beginning in the 1980s, several serologic tests were developed to identify antibody to HEV. Generally, the diagnosis of acute HEV infection is based on the detection of IgM anti-HEV; past infection is determined by the presence of IgG anti-HEV. The first serologic test for anti-HEV utilized IEM [6]. Later, more practical tests were developed, including an immunofluorescence assay [53], which was accompanied by the development of the Western blot $[54,55]$ and enzyme-linked immunosorbent assay [56] based on synthetic peptides and recombinant expressed proteins. Soon after HEV was identified, polymerase chain reaction assays for HEV RNA were developed that have detected HEV genetic material in both stool and serum specimens during active infection $[57,58]$. HEV does not grown well in cell culture [59].

None of these tests for HEV infection are commercially available in the United States. The lack of a licensed test undoubtedly has led to under-reporting of this infection in North America. Serologic tests for anti-HEV are marketed in Europe and in some countries in Asia but are not routinely employed. They are too expensive for use in many developing regions, adding to the under-reporting [60]. Furthermore, HEV infection may have been underdiagnosed because of the low sensitivity of many serologic tests, which is more of a problem in evaluation of populations in nonendemic countries [61].

\section{Prophylaxis and Treatment}

There is no proven prophylaxis for HEV infection. Pooled immune serum globulin has not proven effective in humans, even when produced from donors residing in endemic countries [62]. The best personal preventive measure is avoidance of fecally contaminated water and food. Absent a vaccine, community prevention and control efforts in endemic areas depend on the development of infrastructure to provide potable water [63]. Once hepatitis E develops, medical care is supportive for this self-limited infectious disease. 
Vaccine development

In primate models, HEV infection was found to be associated with immunity to reexposure with different isolates over a period of several years [64-66]. Humans also appear to be protected from hepatitis $\mathrm{E}$ after a prior HEV infection $[49,50]$. These findings indicate that it might be possible to develop a vaccine against hepatitis E. In fact, the two most dynamic areas of current HEV research are vaccine development $[67 \bullet \bullet]$ and the study of possible zoonotic reservoirs of HEV infection [68].

Because HEV does not replicate well in cell culture, vaccine development has focused on recombinant vaccines. Candidate vaccines against hepatitis $\mathrm{E}$ have been formulated that consist of capsid proteins (from open reading frame 2) expressed in Escherichia coli and insect cells. In early studies, cynomolgus monkeys were protected against hepatitis $\mathrm{E}$ by active immunization [51,69]. In further studies of nonhuman primates, baculovirus-expressed capsid protein vaccines protected against hepatitis following heterologous challenge but not always against high-dose challenge $[70 \bullet 71]$. One candidate vaccine was not effective when given 48 hours after HEV exposure [70•].

A baculovirus-expressed capsid vaccine has undergone phase I clinical trials and has now entered phase II/III testing [67••]. In initial testing, the vaccine was immunogenic and did not cause serious side effects. Based on studies in nonhuman primates, the vaccine should provide protective immunity against disease and possibly against infection. The duration of immunity after an initial series of immunizations is a critical factor that will have to be determined in future studies. Another critical factor will be the efficacy of the vaccine against heterologous strains of HEV.

\section{Conclusions}

The study of hepatitis $\mathrm{E}$ has been an instructive story of recent advancements in medical science. Substantial progress has been made in a short period of time through both epidemiologic studies and basic research, which has relied on modern cloning and recombinant technology. New tools have clearly accelerated the pace of research. Within less than two decades of the discovery of HEV, the major epidemiologic features of this unique pathogen have been described, serologic tests have been developed, and a candidate vaccine has been evaluated in an initial clinical trial. Nevertheless, there are still many mysteries about the epidemiology, pathogenesis, and immune response of HEV infection.

The unknown aspects of hepatitis E could have a major impact on vaccine development and use. However, vaccine research could also illuminate the immunologic and epidemiologic characteristics of this unique infectious disease. The development of an animal model of HEV infection in the laboratory would aid research efforts substantially.

It is likely that a HEV vaccine will be developed that provides at least short-term protection from disease. Who will make and buy this vaccine? Because the incidence of acute HEV infection among travelers from the developed world to endemic countries has been estimated to be less than one in a million [33•], the market for this vaccine in nonendemic countries will be limited [72]. Pregnant women living in endemic regions may derive the greatest benefit from an effective HEV vaccine. Whether developing countries would establish vaccination programs that target only a small segment of their population is unknown. Much will depend on whether manufacturers can produce an affordable vaccine for use in countries with limited health-care budgets [63].

\section{References and Recommended Reading}

Papers of particular interest, published recently,

have been highlighted as:

- Of importance

-• Of major importance

1. Purcell RH, Alter HJ, Dienstag JL: Non-A, non-B hepatitis. Yale J Biol Med 1976, 49:243-250.

This important article reveals how far we have come in our understanding of viral hepatitis-particularly non-A, non-B hepatitis-in just the last 25 years. Very little was known about non-A, non-B hepatitis in 1976, including whether it was caused by just one virus or by multiple infectious agents.

2. Aggarwal R, Krawczynski K: Hepatitis E: an overview and recent advances in clinical and laboratory research. J Gastroenterol Hepatol 2000, 15:9-20.

3. Khuroo MS: Study of an epidemic of non-A, non-B hepatitis: possibility of another human hepatitis virus distinct from posttransfusion non-A, non-B type. Am J Med 1980, 68:818-824.

4. Wong DC, Purcell RH: Sreenivasan MA, et al.: Epidemic and endemic hepatitis in India: evidence for non-A, non-B hepatitis virus aetiology. Lancet 1980, 2:876-878.

5. Kane MA, Bradley DW, Shrestha SM, et al.: Epidemic non-A, non-B hepatitis in Nepal: recovery of a possible etiologic agent and transmission studies in marmosets. JAMA 1984, 252:3140-3145.

$6 . \bullet$ Balayan MS, Andjaparidze AG, Savinskaya SS, et al.: Evidence for a virus in non-A, non-B hepatitis transmitted via the fecal-oral route. Intervirology 1983, 20:23-31.

This paper reports on one of the most important studies in HEV research. The authors demonstrated conclusively that a unique virus, distinct from HAV, caused enterically transmitted viral hepatitis. The study also led to a crude serologic test for HEV infection. Although this study was conducted less than two decades ago, it probably could not be repeated now because a volunteer was intentionally infected with a potentially fatal agent. Although the volunteer was one of the study investigators, there is little likelihood that an institutional review board would approve this study today.

7. Reyes GR, Purdy MA, Kim JP, Luk KC, et al.: Isolation of a cDNA from the virus responsible for enterically transmitted non-A, non-B hepatitis. Science 1990, 247:1335-1339.

8. Tam AW, Smith MM, Guerra ME, et al.: Hepatitis E virus (HEV): molecular cloning and sequencing of the full-length viral genome. Virology 1991, 185:120-131.

9. Tsarev SA, Emerson SU, Reyes GR, et al.: Characterization of a prototype strain of hepatitis E virus. Proc Natl Acad Sci U S A 1992, 89:559-563.

10. Berke T, Matson DO: Reclassification of the Caliciviridae into distinct genera and exclusion of hepatitis $\mathrm{E}$ virus from the family on the basis of comparative phylogenetic analysis. Arch Virol 2000, 145:1421-1436.

11. Schlauder GG, Frider B, Sookoian S, et al.: Identification of 2 novel isolates of hepatitis E virus in Argentina. J Infect Dis 2000, 182:294-297. 
12. Schlauder GG, Mushahwar IK: Genetic heterogeneity of hepatitis E virus. J Med Virol 2001, 65:282-292.

13. Purcell RH, Emerson SU: Animal models of hepatitis A and E. ILAR J 2001, 42:161-177.

14. - Meng XJ, Purcell RH, Halbur PG, et al.: A novel virus in swine is closely related to the human hepatitis E virus. Proc Natl Acad Sci U S A 1997, 94:9860-9865.

This article reports a study confirming that pigs are infected with a virus very similar to human $\mathrm{HEV}$.

15. Kabrane-Lazizi Y, Fine JB, Elm J, et al.: Evidence for widespread infection of wild rats with hepatitis $\mathrm{E}$ virus in the United States. Am J Trop Med Hyg 1999, 61:331-335.

16. Haqshenas G, Shivaprasad HL, Woolcock PR, et al.: Genetic identification and characterization of a novel virus related to human hepatitis $\mathrm{E}$ virus from chickens with hepatitis-splenomegaly syndrome in the United States. J Gen Virol 2001, 82:2449-2462.

17.• Schlauder GG, Dawson GJ, Erker JC, et al.: The sequence and phylogenetic analysis of a novel hepatitis $\mathrm{E}$ virus isolated from a patient with acute hepatitis reported in the United States. J Gen Virol 1998, 79:447-456.

Although only a case report, this study is significant because it clearly indicates that humans may be infected with swine HEV, suggesting that hepatitis $\mathrm{E}$ might be a zoonotic disease.

18. Meng XJ, Halbur PG, Shapiro MS, et al.: Genetic and experimental evidence for cross-species infection by swine hepatitis E virus. J Virol 1998, 72:9714-9721.

19. Meng XJ, Halbur PG, Haynes JS, et al.: Experimental infection of pigs with the newly identified swine hepatitis $\mathrm{E}$ virus (swine HEV), but not with human strains of HEV. Arch Virol 1998, 143:1405-1415.

20. Meng XJ: Novel strains of hepatitis E virus identified from humans and other animal species: is hepatitis $\mathrm{E}$ a zoonosis? $J$ Hepatol 2000, 33:842-845.

21. Centers for Disease Control: Enterically transmitted non-A, non-B hepatitis-Mexico. MMWR Morb Mortal Wkly Rep 1987, 36:597-602.

22. Meng H: A food-borne outbreak of non-A non-B hepatitis. Zhonghua Yu Fang Yi Xue Za Zhi 1987, 21:28-30.

23. Aggarwal R, Naik SR: Hepatitis E: Intrafamilial transmission versus waterborne spread. J Hepatol 1994, 21:718-723.

24. Khuroo MS, Kamili S, Jameel S: Vertical transmission of hepatitis E virus. Lancet 1995, 345:1025-1026.

25. Psichogiou M, Tzala E, Boletis J, et al.: Hepatitis E virus infection in individuals at high risk of transmission of non-A, non-B hepatitis and sexually transmitted diseases. Scand $J$ Infect Dis 1996, 28:443-445.

26. Barzilai A, Schulman S, Karetnyi YV, et al.: Hepatitis E virus infection in hemophiliacs. J Med Virol 1995, 46:153-156.

27. Bile $\mathrm{K}$, Isse $\mathrm{A}$, Mohamud $\mathrm{O}$, et al.: Contrasting roles of rivers and wells as sources of drinking water on attack and fatality rates in a hepatitis E epidemic in Somalia. Am J Trop Med Hyg 1994, 51:466-474.

28. Corwin AL, Tien NTK, Bounlu $\mathrm{K}$, et al.: The unique riverine ecology of hepatitis E virus transmission in Southeast Asia. Trans R Soc Trop Med Hyg 1999, 93:255-260.

29. Corwin AL, Khiem HB, Clayson ET, et al.: A waterborne outbreak of hepatitis E virus transmission in Southwestern Vietnam. Am J Trop Med Hyg 1996, 54:559-562.

30. Corwin A, Jarot K, Lubis I, et al.: Two years' investigation of epidemic hepatitis $\mathrm{E}$ virus transmission in West Kalimantan (Borneo), Indonesia. Trans R Soc Trop Med Hyg 1995, 89:262-265.

31. Tsega E, Hansson B-G, Krawczynski K, Nordenfelt E: Acute sporadic viral hepatitis in Ethiopia: causes, risk factors, and effects on pregnancy. Clin Infect Dis 1992, 14:961-965.

32. Hyams KC, McCarthy MC, Kaur M, et al.: Acute sporadic hepatitis E in children living in Cairo Egypt. J Med Virol 1992, 37:274-277.

33. Piper-Jenks N, Horowitz HW, Schwartz E: Risk of hepatitis E infection to travelers. J Travel Med 2000, 7:194-199.

This article provides an excellent overview of the epidemiology of hepatitis $\mathrm{E}$ and the risk of infection for travelers.
34. Fix AD, Abdel-Hamid M, Purcell RH, et al.: Prevalence of antibodies to hepatitis $\mathrm{E}$ in two rural Egyptian communities. Am J Trop Med Hyg 2000, 62:519-523.

35. Centers for Disease Control: Hepatitis E among U.S. travelers, 1989-1992. MMWR Morb Mortal Wkly Rep 1993, 42:1-4.

36. Mast EE, Kuramoto IK, Favorov MO, et al.: Prevalence of and risk factors for antibody to hepatitis $\mathrm{E}$ virus seroreactivity among blood donors in Northern California. J Infect Dis 1997, 176:34-40.

37. Skidmore SJ, Sherratt LM: Hepatitis E infection in the UK. J Viral Hepat 1996, 3:103-105.

38. Drobeniuc J, Favorov MO, Shapiro CN, et al.: Hepatitis E virus antibody prevalence among persons who work with swine. $J$ Infect Dis 2001, 184:1594-1597.

39. Smalligan $\mathrm{RD}$, Lange WR, Frame JD, et al.: The risk of viral hepatitis A, B, C, and E among North American missionaries. Am J Trop Med Hyg 1995, 53:233-236.

40. Burans JP, Sharp T, Wallace M, et al:: The threat of hepatitis E virus infection in Somalia during Operation Restore Hope. Clin Infect Dis 1994, 18:100-102.

41. Buisson $Y$, Coursaget $P$, Bercion R, et al.: Hepatitis $E$ virus infection in soldiers sent to endemic regions. Lancet 1994, 344:1165-1166.

42. Alecci A, Bonciani M, Tola T: Prevalence of anti-HEV among Italian soldiers sent in East Africa for Restore Hope' mission. Eur J Epidemiol 1997, 13:735.

43. Soe S, Uchida T, Suzuki K, et al.: Enterically transmitted non-A non-B hepatitis in cynomolgus monkeys: morphology and probable mechanism of hepatocellular necrosis. Liver 1989, 9:135-145.

44. Tsarev SA, Tsareva TS, Emerson SU, et al.: Infectivity titration of a prototype strain of hepatitis $\mathrm{E}$ virus in cynomolgus monkeys. J Med Virol 1994, 43:135-142.

45. Mushahwar IK, Dawson GJ, Bile KM, Magnius LO: Serological studies of an enterically transmitted non-A, non-B hepatitis in Somalia. J Med Virol 1993, 40:218-221.

46. Hyams KC, Purdy MA, Kaur M, et al.: Acute sporadic hepatitis $E$ in Sudanese children: analysis based on a new western blot assay. J Infect Dis 1992, 165:1001-1005.

47. Nanda SK, Yalcinkaya K, Panigrahi AK, et al.: Etiological role of hepatitis $\mathrm{E}$ virus in sporadic fulminant hepatitis. J Med Virol 1994, 42:133-137.

48. Hussaini SH, Skidmore SJ, Richardson P, et al.: Severe hepatitis E infection during pregnancy. J Viral Hepatol 1997, 4:51-54.

49. Khuroo MS, Kamili S, Dar MY, et al:: Hepatitis E and long-term antibody status. Lancet 1993, 341:1355.

50. Bryan JP, Tsarev SA, Iqbal M, et al.: Epidemic hepatitis $\mathrm{E}$ in Pakistan: patterns of serologic response and evidence that antibody to hepatitis $\mathrm{E}$ virus protects against disease. J Infect Dis 1994, 170:517-521.

51. Tsarev SA, Tsareva TS, Emerson SU, et al.: Successful passive and active immunization of cynomolgus monkeys against hepatitis E. Proc Natl Acad Sci U S A 1994, 91:10198-10202.

52. Pillot J, Turkoglu S, Dubreuil P, et al.: Cross-reactive immunity against different strains of the hepatitis $\mathrm{E}$ virus transferable by simian and human sera. C R Acad Sci III 1995, 318:1059-1064.

53. Krawczynski K, Bradley DW: Enterically transmitted non-A, non-B hepatitis: identification of virus-associated antigen in experimentally infected cynomolgus macaques. J Infect Dis 1989, 159:1042-1049.

54. Purdy MA, McCaustland KA, Krawczynski K, et al.: Expression of a hepatitis E virus (HEV)-trpE fusion protein containing epitopes recognized by antibodies in sera from human cases and experimentally infected primates. Arch Virol 1992, 123:335-349.

55. He J, Tam AW, Yarbough PO, Reyes GR, Carl M: Expression and diagnostic utility of hepatitis E virus putative structural proteins expressed in insect cells. J Clin Microbiol 1993, 31:2167-2173.

56. Tsarev SA, Tsareva TS, Emerson SU, et al.: ELISA for antibody to hepatitis E virus (HEV) based on complete open-readying frame-2 protein expressed in insect cells: identification of HEV infection in primates. J Infect Dis 1993, 168:369-378. 
57. McCaustland KA, Bi S, Purdy MA, Bradley DW: Application of two RNA extraction methods prior to amplification of hepatitis $\mathrm{E}$ virus nucleic acid by the polymerase chain reaction. $J$ Virol Methods 1991, 35:331-342.

58. Aggarwal R, McCaustland KA: Hepatitis E virus RNA detection in serum and feces specimens with the use of microspin columns. J Virol Methods 1998, 74:209-213.

59. Tam AW, White R, Yarbough PO, et al.: In vitro infection and replication of hepatitis $\mathrm{E}$ virus in primary cynomolgus macaque hepatocytes. Virology 1997, 238:94-102.

60. McCrudden R, O'Connell S, Farrant T, et al.: Sporadic acute hepatitis $\mathrm{E}$ in United Kingdom: an underdiagnosed phenomenon? Gut 2000, 46:732-733.

61. Mast EE, Alter MJ, Holland PV, Purcell RH: Evaluation of assays for antibody to hepatitis E virus by a serum panel: Hepatitis E Virus Antibody Serum Panel Evaluation Group. Hepatology 1998, 27:857-861

62. Khuroo MS, Dar MY: Hepatitis E: evidence for person-to-person transmission and inability of low dose immune serum globulin from an Indian source to prevent it. Indian J Gastroenterol 1992, 11:113-116.

63. Stevenson P: Nepal calls the shots in hepatitis $E$ virus vaccine trial. Lancet 2000, 355:1623.

64. Arankalle VA, Favorov MO, Chadha MS, et al.: Rhesus monkeys infected with hepatitis E virus (HEV) from the former USSR are immune to subsequent challenge with an Indian strain of HEV. Acta Virol 1993, 37:515-518.

65. Arankalle VA, Chadha MS, Chobe LP, et al.: Cross-challenge studies in Rhesus monkeys employing different Indian isolates of hepatitis E virus. J Med Virol 1995, 46:358-363.
66. Arankalle VA, Chadha MS, Chobe LP: Long-term serological follow up and cross-challenge studies in rhesus monkeys experimentally infected with hepatitis E virus. J Hepatol 1999, 30:199-204.

67.• Emerson SU, Purcell RH: Recombinant vaccines for hepatitis E. Trends Molec Med 2001, 7:462-466

This excellent article should be compared with that of Purcell et al. [1•] to understand how far we have come in our understanding of non-A, non-B hepatitis in the last 25 years. Of note, one of the authors of the original paper is still one of the most productive investigators in the field of hepatitis $\mathrm{E}$ research.

68. Meng XJ, Wiseman B, Elvinger F, et al.: Prevalence of antibodies to hepatitis $E$ virus in veterinarians working with swine and in normal blood donors in the United States and other countries. J Clin Microbiol 2002, 40:117-122.

69. Purdy MA, McCaustland KA, Krawczynski K, et al.: Preliminary evidence that a trpE-HEV fusion protein protects Cynomolgus macaques against challenge with wild-type hepatitis $\mathrm{E}$ virus (HEV). J Med Virol 1993, 41:90-94.

70. Tsarev SA, Tsareva TS, Emerson SU, et al.: Recombinant vaccine against hepatitis E: dose response and protection against heterologous challenge. Vaccine 1997, 15:1834-1838.

This important study indicates that a hepatitis $\mathrm{E}$ vaccine based on the capsid protein would be broadly effective against different strains from different regions. Interestingly, the hepatitis E vaccine was not effective following exposure, unlike the hepatitis A vaccine.

71. Zhang M, Emerson SU, Nguyen $\mathrm{H}$, et al.: Immunogenicity and protective efficacy of a vaccine prepared from $53 \mathrm{kDa}$ truncated hepatitis E virus capsid protein expressed in insect cells. Vaccine 2001, 20:853-857.

72. Shlim DR, Innis BL: Hepatitis E vaccine for travelers? J Travel Med 2000, 7:167-169. 